\title{
LOS ROMANCES DE GAZUL
}

En los dos últimos decenios del siglo xvi el Romancero adquiere nueva vitalidad merced al gusto que se despierta por el cultivo del romance en los poetas jóvenes que habían de elevar a la mayor altura nuestras letras. Siguen escribiendo romances sobre personajes históricos y asuntos legendarios españoles y extranjeros (el rey Rodrigo, los condes de Carrión, el Cid, Carlomagno, Eneas), pero aparecen nuevos asuntos: de cautivos, forzados, capitanes africanos, y especialmente el género morisco que durante unos pocos años tuvo exuberante prolificación.

Es corriente considerar los romances moriscos como una variación de los fronterizos, y acaso contribuyó a esta confusión Ginés Pérez de Hita, que en las Guerras civiles de Granada $(1595)^{1}$ mezcló los dos géneros para ilustrar su obra, sin hacer distinción entre los romances viejos tradicionales y los recién compuestos (a veces llama viejos a estos últimos), alterándolos o imitándolos a su albedrío. A poco que nos fijemos, hallaremos cuán diferente es la inspiración de unos y la de otros, hasta el punto de que realmente no tienen de común sino algunos nombres más o menos arabizados de personajes y de costumbres. En los romances fronterizos se relata brevemente una acción bélica ocurrida en la frontera (de ahí su denominación) o el efecto por ella producido entre los dos pueblos contendientes. Son verdaderos noticiarios de sucedidos, siendo éstos a veces de tan escasa importancia que los cronistas contemporáneos no los mencionan. En los romances moriscos hay también disputas entre rivales, pero no se trata de conquistar o defender fortalezas, sino damas; el móvil suele ser los celos o los desdenes. Los protagonistas se comportan como caballeros enamorados que se desafían de palabra. En muy pocas ocasiones llegan a combatir. La descripción de fiestas, la enumeración de vestiduras con alarde de nombres árabes (albornoces, almaizares, marlotas, jacerinas, alquiceles), los ricos jaeces, las medallas, los motes y las empresas dan brillantez. y un tono jovial a los relatos.

Los poetas no tenían que inventar todo este ambiente festivo,

${ }^{1}$ Citaré siempre esta obra por la edición de Paula Blanchard-Demouge, Madrid, 1913 . 
ni buscarlo en la tradición mora. Hacía tiempo que los cristianos, aun antes que hubiesen terminado la Reconquista, habían adoptado trajes e imitado festejos de los musulmanes. Los juegos de cañas, que vinieron a sustituir al romper lanzas en los torneos, fueron número obligado en todos los festejos públicos durante muchos años, y en ellos los caballeros montaban a la jineta y calzaban borceguíes con acicate. El albornoz era vestidura obligada de sus cuadrillas. Las vestiduras moriscas se pusieron de moda; no sólo el degenerado Enrique IV se ataviaba con prendas moras, sino que documentan ese uso estatuas yacentes de sepulcros de ilustres personajes, tal la que representa a Gómez Manrique tocado con turbante, que puede verse en el Museo de Burgos. En la detallista Crónica del condestable Miguel Lucas de Iranzo hay multitud de datos sobre esas fiestas y vestiduras moras adoptadas por los caballeros de Jaén. El mismo Condestable en día de regocijo iba recorriendo las calles de la ciudad cabalgando a la jineta y ataviado con una aljuba morisca de seda de muchos colores, y daba como premio a los caballeros que se distinguían en los juegos "camisas moriscas, e tocas tunecís, e gentiles almaizares o capirotes moriscos"' 2 No es de extrañar que los poetas se inspirasen poco más tarde en esas costumbres para dar colorido a sus romances, y que éstos fuesen bien recibidos.

La Flor de romances recopilada por Andrés de Villalta, con licencia fechada en $15^{88}$, es la primera colección conocida en que aparecen romances propiamente moriscos. No existen en los Cancioneros, ni en las Silvas de mediados del siglo xvi, ni en las Rosas de Timoneda de 1573, ni menos en el Romancero de Pedro de Padilla de 1583 .

Las Flores propagaron el Romancero Nuevo, recogiendo los pliegos sueltos y los cuadernos en que debieron publicarse de primera intención los romances que se iban componiendo. Así lo habian hecho los compiladores del Cancionero de romances. La publicación de las Flores fué un éxito editorial; las partes se sucedían unas a otras sin cesar, y en distintas poblaciones; su pequeño formato de doce por seis centímetros (contenían poco más de medio centenar de versiones) facilitaba su manejo; las doncellas podían ocultarlas en sus mangas y los donceles en sus esqueros. El estudio de las Flores está por hacer; los ejemplares conservados son pocos y están esparcidos por diversas bibliotecas del mundo. Desde luego, los primeros editores se apropiaban las colecciones de los otros, introduciendo algunas variaciones, especialmente en los prólogos.

En 1600 se publicó el Romancero general, dividido en nueve partes que vienen a reproducir sobre poco más o menos nueve Flores, y en 1604 el Romancero recoge otras cuatro Flores. La corres-

${ }^{2}$ Edición de J. de Mata Carriazo, pág. 117. 
pondencia de las trece partes del Romancero general no es exacta con las trece Flores, porque algunos romances faltan y se añaden otros. La Flor de 1588 manifiesta el auge que habían alcanzado los romances moriscos, ya que ocupan más de la tercera parte del libro. La moda no duró mucho, pues a medida que pasamos revista a los años de publicación de las Flores, vemos que disminuyen los romances moriscos y aumentan las sátiras contra ellos. En las cuatro últimas partes que añadió el Romancero de 1604 sólo hay un romance morisco.

Cuando a principios del siglo xix los románticos ingleses y alemanes hicieron el descubrimiento de nuestro Romancero, que nosotros teníamos arrinconado, se sintieron deslumbrados por la brillantez de los romances moriscos, que conocieron en su mayor parte a través de las Guerras civiles, y los consideraron como supervivencia de la historia del pueblo árabe, que convivió tantos años con el español cristiano. Es verdad que esos relatos están inspirados en sucesos vividos, pero nada tienen de historia nacional, sino que contienen datos autobiográficos transfigurados por la imaginación de sus mismos autores, que manifestaban en ellos sus pasiones y escarceos amorosos.

Los romances moriscos forman ciclos agrupándose alrededor de un protagonista. El ciclo de Gazul es uno de los primeros que aparecen y es de los más prolíferos y difundidos. No dudamos en prohijar a Lope los principales, pues sabemos que se había alzado con el cetro del Romancero antes de alzarse con la monarquía cómica.

Siempre gustó nuestro poeta de que su vida íntima asomase en sus obras; sobre todo en su primera juventud parece que no puede desasirse totalmente de la realidad que le rodea, y, empapada en ella, su imaginación crea y recrea mil situaciones, análogas en el fondo, pero siempre dispares en la forma. De esas múltiples proyecciones y algunos datos históricos, sacaremos un esquema que es como un cañamazo en que veremos representados los más diversos cuadros.

Lope de Vega se encontraba estudiando en Alcalá -según parece, no en la Universidad, sino en algún colegio- bajo la protección del obispo don Jerónimo Manrique. Llega un momento en que el escolar, sintiendo que no es aquélla su vocación, ahorca los hábitos (ca. 1580) y empieza la ocupación amorosa que, hermanada con el cultivo de las letras, le durara toda su larga y fecunda vida. La primera novia (la llamaremos Marfisa, tomando el nombre que lleva en la Dorotea) fué una vecinita aún más joven que él: la novia de la adolescencia, la mujer indiferenciada, la que se puso a tiro, "sin más gracias que desearlas", como nos dirá en una ocasión; amores lánguidos, que se prolongaban sin que se viese el término.

En 1583 ocurre un suceso nacional que conmueve a la juventud; ésta siente llegado el momento de acudir con las armas a la empresa 
que habrá de dar fin a la resistencia de los portugueses, apoyados por los franceses, para que en Felipe II queden unidos los dos reinos peninsulares. Lope embarca en Lisboa el 29 de junio de 1583 en la armada que parte a las Islas Terceras bajo el mando del egregio Marqués de Santa Cruz. Pasados tres meses escasos desembarca en Cádiz, y con la alegría de la victoria llega a Madrid, donde encuentra a Marfisa a punto de casarse. Primer fracaso amoroso; algo le consuela el saber que la amada ha tenido que doblegarse a la voluntad de sus deudos, los cuales han aprovechado la ausencia de ese joven sin oficio ni beneficio, para desposarla con un hombre rico, aunque viejo. Desde este momento la pobreza empieza a ser una obsesión de Lope; de ella nos hablará muchas veces en sus obras juveniles.

El marido de Marfisa, siguiendo la suerte de muchos viejos casados con moza, se olvidó de sus años y agotó pronto su vida. La viudita volvió a su casa sin gran pena, porque casó sin gusto, y faltó tiempo para que el trato engendrase cariño. Además, abrigaba la esperanza de empalmar su primer amor. Pero Lope se había consolado rápidamente del desvío sufrido, porque "como no fué amor de peso, púdolo el viento llevar", y sobre todo porque al momento halló doblado consuelo, enredándose en los lazos avasalladores de Elena Osorio y dando comienzo a una pasión que dejó en su corazón huellas indelebles. Sin embargo, siguió algún tiempo el trato de Marfisa, como recurso reparador de las veleidades de Elena.

Estas primeras experiencias amorosas, como luego la tempestuosa temporada de la pasión por Elena, sirvieron de inspiración a multitud de versos y relatos del poeta que se hallan esparcidos por sus obras. El mismo tema lo encontramos tratado por extenso en dos tempranas comedias pastoriles: El verdadero amante y Belardo el furioso, y en el primer acto de El galán escarmentado. No es $\mathrm{mi}$ propósito analizar ahora esas comedias juveniles, sino sólo recordarlas, así como también La Dorotea (una de las primeras y de las últimas obras de Lope), porque ilustran los romances que voy a estudiar ${ }^{3}$.

El ciclo de Gazul está formado por una serie de cuadritos líricodramáticos en que interviene el protagonista de Sidonia (=Lope

${ }^{3}$ Respecto a $E l$ verdadero amante, no se da crédito alguno a la indicación que hace su autor en el prólogo que puso al publicar la comedia en 1619, de la que se desprende que la escribió a los 12 años. Más que un alarde de precocidad es una de tantas confusiones en que incurría Lope siempre que manejaba números. Esta comedia no puede ser anterior al comienzo del trato con Elena (1583). En cuanto a El galán escarmentado hay que observar que el primer acto debemos estudiarlo aparte de los otros dos, tanto por la forma como por el contenido. Es una de tantas comedias que el Fénix no escribió de un tirón: no todas "en horas veinticuatro / pasaron de las Musas al teatro". 
de Vega) y Zaida de Jerez (=Marfisa), Celinda de Sanlúcar (=Elena) y Albenzaide, marido de Marfisa.

Hasta veinte romances de Gazul incluye Durán en su Romancero ( $B A A E E$, vol. $\mathrm{X}$, págs. 12-23), y aún tengo copiados algunos más procedentes de manuscritos del siglo xvi y otros recogidos de la tradición oral. Desde luego no todos son de Lope; le prohijaremos sólo los que se puedan apoyar en datos que el poeta nos proporciona en otras obras suyas. Pueden dividirse en dos grupos. El primero tiene por núcleo la defección de Zaida y la pronta muerte del marido, seguida de las maldiciones de la viuda. El segundo comprende el comienzo de los amores con la Osorio, celos de las dos mujeres, riñas y reconciliaciones. Dan unidad al conjunto los preparativos para un juego de cañas en que Gazul hace alarde de gallardía y obtiene brillantes éxitos.

Romance I. Si tan bien arrojas lanzas.-Invectiva de Gazul contra su rival, tildándole de cobarde: no ha de preciarse de su oro, que las armas dan más honra que el dinero. Es una especie de monólogo, al final del cual se declara el nombre del protagonista; esta forma estuvo de moda algún tiempo en el Romancero Nuevo.

$$
\begin{aligned}
& \text { Esto decía Gazul, } \\
& \text { el que la fama pregona, } \\
& \text { puesto en olvido por pobre } \\
& \text { de la bella Zaida mora }{ }^{4} \text {. }
\end{aligned}
$$

Romance II. Cuando de los enemigos.-Se dirige contra la ingrata, que, mientras él, vistiendo malla sangrienta, defendía las riberas atacadas por los enemigos, se abandonó en brazos ajenos. Pero no tardará en hallar su castigo:

¡qué contento será verte cuando llegues a abrazallo, mezcladas tus trenzas rubias entre su copete blanco!

Pronto ella echará de menos el tiempo pasado y de nada le servirá alegar que dió el sí forzada, "que donde amor se atraviesa / no hay padres reverenciados". Es un monólogo que hace pareja con el anterior romance.

Romance III. Limpiame la jacerina.-Gazul pide que le preparen vestidos y arreos que pongan de manifiesto su pesar por el abandono de Zaida: negras han de ser las plumas de su bonete, los

4 Impreso en la cuarta parte del Romancero de 1600. 
diamantes del albornoz amarillo serán sustituídos por azabaches, el alfanje ha de ir en negra vaina y tinta negra cubrirá los esmaltes de los acicates. Armado con la lanza de dos hierros va en busca de su rival, porque le han dicho que

se casa su bella mora

con su enemigo Albenzaide, moro rico de nación, aunque de torpe linaje; pero venció la riqueza a tres años de amistades.

Los cuatro últimos versos enlazan este romance con el núm. IV:

La primer señal de Venus mostrando su estrella sale, cuando sale de Sidonia y para Jerez se parte.

El haberse publicado en la parte $6^{\mathrm{a}}$ del Romancero de 1600 , que debe proceder de la 6 a Flor que lleva la fecha de 1593 , nos hace sospechar que se escribió más tarde que el IV.

Romance IV. Sale la estrella de Venus.-Es el principal de la serie y el de mayor fama y difusión. Escrito con brío, manifiesta el furor de Gazul, que se venga de la ingratitud de Zaida dando muerte a su rival en plena fiesta de la noche de la boda. En las dos comedias pastoriles castigan injustamente al protagonista por la sospecha de que ha sido causa de la muerte del recién desposado.

Aunque por su asunto los tres primeros romances pueden considerarse como preliminares, no necesariamente se escribieron antes del núm. IV; acaso fueron consecuencia de la fama adquirida por La estrella de Venus. Copio a continuación el romance, porque tendré que hacer referencia a varios versos ${ }^{5}$.

1 Sale la estrella de Venus al tiempo que el sol se pone, y la enemiga del día su negro manto descoge;

5 y con ella un fuerte moro semejante a Rodamonte sale de Sidonia airado, de Jerez la vega corre, por donde entra Guadalete

10 al mar de España, y por donde Santa María del Puerto recibe famoso nombre. Desesperado camina, que siendo en linaje noble,

5 Romancero general de 1600 , primera parte. Procede de la primera Flor de ${ }_{15} 88$. Otra versiói con pocas variantes se encuentra en el ms. 3168 de la B. N. M. (años $15^{82}$ a 1600 ). En la $1^{n}$ parte del Jardin de amadores de 1679 hay una versión con bastantes variantes, que en nada mejora el texto viejo. 
15 le deja su dama ingrata porque se suena que es pobre, y aquella noche se casa con un moro feo y torpe, porque es alcaide en Sevilla

20 del alcázar y la torre, quejándose tiernamente de un agravio tan enorme, y a sus palabras la vega con dulces ecos responde:

25 "Zaida, dice, más airada que el mar que las naves sorbe, más dura $\mathrm{e}$ inexorable que las entrañas de un monte, ¿Cómo permites, cruel,

3o después de tantos favores, que de prendas de mi alma ajena mano se adorne? ¿Es posible que te abraces a las cortezas de un roble

35 y dejes el árbol tuyo desnudo de fruto y flores? Dejas tu amado Gazul, dejas tres años de amores, y das la mano a Albenzaide,

40 que aun apenas le conoces; dejas un pobre muy rico, $\mathrm{y}$ un rico muy pobre escoges, pues las riquezas del cuerpo a las del alma antepones.

45 Alá, permita, enemiga, que te aborrezca y le adores, y que por celos suspires, y por ausencia le llores; y que de noche no duermas,

$5^{\circ}$ y de día no reposes, y en la cama le fastidies, y que en la mesa le enojes; y en las fiestas, en las zambras no se vista tus colores,

55 ni aun para verlas permita que a la ventana te asomes; y menosprecie en las cañas (para que más te alborotes) el almaizar que le labres

6o y la manga que le bordes, y se ponga el de su amiga con la cifra de su nombre, a quien le dé los cautivos cuando de la guerra torne;

$6_{5}$ y en batalla de cristianos de verlo muerto te asombres; y plegue a Alá que suceda, cuando la mano le tomes, que si le has de aborrecer,

7o que largos años le goces, que es la mayor maldición que pueden darte los hombres". Con esto llegó a Jerez

a la mitad de la noche;

75 halló el palacio cubierto de luminarias y voces, y los moros fronterizos que por todas partes corren, con sus hachas encendidas,

80 y con libreas conformes. Delante del desposado en los estribos alzóse; arrojóle una lanzada, de parte a parte pasóle.

85 Alborotóse la plaza, desnudó el moro un estoque, y por mitad de la gente hacia Sidonia volvióse.

Romance V. La bella Zaida Cegri.-Quejas de la esposa y viuda en un punto, y llanto sobre el cuerpo de Albenzaide. Maldice a Gazul deseándole todo género de desdichas, más que apenada, celosa de la amada que él tiene en Sanlúcar. Entre las maldiciones figura una alusión muy velada a un enemigo de Gazul:

y que en medio del camino, cuando tú a Sidonia vayas, encuentres (aunque sea solo) a Garcipérez de Vargas, y que en viéndole te turbes... 
Se trata del hombre que a la sazón ocupaba el primer lugar entre los adoradores de Elena y a quien ella abandonó por preferir a Lope. Es personaje que figura destacadamente en las dos comedias pastoriles y en La Dorotea. Sólo un estudio cuidadoso de romances y otras obras nos deja entrever a este rival, que fué tratado muchas veces con cauteloso miramiento por nuestro poeta.

Romance VI. Del perezoso Morfeo.-Los maldicientes han dicho a Zaida que Gazul intenta matarla. Huye despavorida a caballo, vestida de hombre, y se refugia en Sevilla hasta que se convence de que la noticia es falsa. Es romance tardío, con estribillo, y parece apartarse del tema central. Algunos versos, especialmente los que se refieren a los temores que asaltan por la noche a la fugitiva, son afortunados.

Romance VII. Por la plaza de Sanlúcar.-Es el principal romance de la $2^{\text {a }}$ serie; alrededor de él se pueden agrupar los demás, y es acaso el mejor de los moriscos que escribió Lope. Presenta a Gazul gentilmente ataviado para ir a jugar cañas en unas fiestas que se celebran en Gelves. Para despedirse de Celinda ronda su casa impaciente a caballo, hasta que al fin ella se asoma a la ventana. Gazul hace extremos de acatamiento:

$$
\begin{aligned}
& \text { y arremetiendo el caballo } \\
& \text { por ver el sol que amanece, } \\
& \text { haciendo que se arrodille } \\
& \text { y el suelo en su nombre bese. }
\end{aligned}
$$

A las amorosas palabras de Gazul, Celinda responde desabrida, mostrándose celosa porque le han dicho que él vuelve a querer a Zaida la de Jerez. Es inútil que Gazul se justifique:

$$
\begin{aligned}
& \text { Mi alma aborrece a Zaida } \\
& \text { y de su amor se arrepiente, } \\
& \text { que su desdén y tu amor } \\
& \text { han hecho su fuego nieve. } \\
& \text { Malditos sean tres años } \\
& \text { que la serví por mi suerte, } \\
& \text { y me dejó por un moro } \\
& \text { más rico de pobres bienes. }
\end{aligned}
$$

En lugar de aplacarse, Celinda se irrita más, y maldiciendo al galán, deseándole mala suerte en las cañas, le cierra de golpe la ventana, sin escuchar más. La desesperación de Gazul da asunto a otros romances, pero la insistencia no nos inclina a sospechar que sean de otro autor, pues sabemos que cuando a Lope le obsesiona una idea, escribe multitud de versos sobre ella, sin repetirse nunca en la forma. 
Romance VIII. Cual bravo toro vencido.-Con vestiduras de colores que demuestran su pesar, sin lanza porque la hizo pedazos contra la pared cuando Celinda le cerró la ventana, Gazul sale airado de Sanlúcar. Entra en Gelves tan desesperado que todos le huyen y queda solo en la plaza (Romancero general de $1600,7^{\mathrm{a}}$ parte, fol. $244 c)$.

Romance IX. A media legua de Gelves.-Otro romance en que Gazul, desesperado por las maldiciones de Zaida y de Celinda, comete mil locuras: rompe la lanza (aquí contra un roble), destroza los adornos que lleva, da rienda suelta a su caballo, "y él prosigue su camino / a pie, sin yelmo ni lanza". No añade este romance (Romancero general de $1600,6^{\text {a }}$ parte, fol. $176 c$ ) nada nuevo al asunto de los anteriores, pero tampoco los contradice.

Romance X. En el tiempo que Celinda.-Se arrepiente la mora del desprecio que hizo a Gazul:

$$
\begin{aligned}
& \text { por verle y desagraviarle } \\
& \text { el corazón se le abrasa, } \\
& \text { que en el villano de amor } \\
& \text { es muy cierta esta mudanza, } \\
& \text { y le danzan muchas veces } \\
& \text { los que de veras se aman. }
\end{aligned}
$$

Celinda supo que el moro había mudado su traje por otro de tristes colores y hecho muchos extremos de pesar. Al tener noticia que el juego de cañas se había aplazado, se apresuró a prepararle vistosos atavíos. Con este motivo tenemos una exposición del simbolismo de los colores alegres, como se había hecho de los tristes en romances anteriores. Envía Celinda un paje a llamar a su amado. Éste acude lleno de júbilo a la cita, y encuentra a la mora en el jardín; el poeta aprovecha el escenario para hacer una de esas enumeraciones de flores a que tan aficionado era. Tras de esto, el largo romance termina con la reconciliación de los amantes; él se parte muy alegre a Gelves, vestido con las preseas que le puso Celinda ${ }^{7}$.

Romance XI. De los trofeos de amor.-Descripción de galas y fiestas. Entre las damas que contemplan a Gazul victorioso está Zaida

- Alusión al baile del villano, en uso en aquella época.

7 El romance se publicó ya en la primera Flor de 1588 . Hay otra versión con variantes y acortada (acaso para que fuese cantada) en el cartapacio de Jacinto López, músico de Su Majestad (Madrid, 1620); se conserva en el ms. 1915 de la B. N. M. 
que se conmueve recordando su antiguo amor, perdido por culpa suya. Otra mora amiga trata de confortarla, sin lograrlo. El bullicio del juego pone fin al diálogos.

Romance XiI. Después que el fuerte Gazul.-Al llegar el moro triunfante a Sanlúcar, sale a recibirle amorosamente Celinda, segura de que él ya ha olvidado a Zaida. Con este romance queda terminado el ciclo de Gazul, Zaida y Celinda. Sin embargo, como el nombre de Gazul figura en otro cuyo autor es indudablemente Lope, lo comento a continuación. Es de los más tempranos, pues ya se recogió en la primera Flor.

Romance XIII. Estando toda la corte.-Descripción de una fiesta en que Gazul, con gran destreza, rejonea un toro. Es un cuadrito plástico que entra por los ojos y que se sigue con interés. El encuentro del toro con el caballo está vivamente descrito:

del toro el aliento frío el rostro al caballo espanta, y la espuma del caballo al toro ofende la cara...

Sigue luego el retrato acabado de un toro bravo:

$$
\begin{aligned}
& \text { famoso entre la manada ..., } \\
& \text { bayo, el color encendido, } \\
& \text { los ojos como la brasa, } \\
& \text { arrugado el corto cuello, } \\
& \text { la frente vellosa y ancha, } \\
& \text { poco distantes los cuernos, } \\
& \text { corta pierna y flaca el anca, } \\
& \text { espacioso el fuerte pecho } \\
& \text { a quien se junta la barba, } \\
& \text { todos los extremos negros, } \\
& \text { la cola revuelta y larga, } \\
& \text { lomo duro y pelo crespo, } \\
& \text { la piel sembrada de manchas. }
\end{aligned}
$$

El Gazul de esta composición no representa a Lope, sino a un hijo del Marqués de Algaba que, según sabemos por los historiadores, era famoso rejoneador. Al comienzo se cita a Gazul como descendiente del alcaide del Algaba; termina con estos versos:

${ }^{8}$ En la primera Flor y en el Romancero de 1600 se llama "Celinda" a la dama por errata, pues en el mismo texto se la apellida "la de Jerez". 
porque otra cosa no escucha

por andamios y ventanas

sino que fué grande suerte

del famoso del Algaba".

Hay varios otros romances en que figura como protagonista Gazul y como sucesos sus amores con Zaida o Celinda, pero que no pertenecen al ciclo estudiado; por ejemplo, Guillén de Castro leyó en la Academia de los Nocturnos de Valencia un romance en que Gazul, enojado con la infiel Zaida, desafía a su rival y a cuantos le han ofendido ${ }^{10}$.

Otro romance, publicado en la primera Flor, trata de cómo al volver Gazul de la guerra contra Zulema, encuentra a su esposa triste y enojada porque él, durante su ausencia, no le ha escrito. Después de oír la disculpa se reconcilian. Este romance se relaciona con el anterior de Castro por introducir el nombre de Zulema, que no se encuentra en las composiciones de Lope, y por tener a Granada por escenario $^{11}$.

Ginés Pérez de Hita contribuyó mucho a la difusión de los romances del ciclo de Gazul con su novela Guerras civiles de Granada. Entre la turbamulta de sucesos, cuenta los amores de Gazul y Lindaraja, nombre éste que viene a sustituir al de Zaida. Incluye varios romances que se habían publicado en la primera parte de las Flores, y según su costumbre, unos van copiados casi a la letra y otros sustituídos por versos suyos adaptados al asunto. Los romances que en la obra de Pérez de Hita adornan la historia de Gazul, desarrollada en varios capítulos sucesivos, son los siguientes:

1) Por la plaza de Sanlúcar.-Es, con muy ligeras variantes, el mismo de Lope de Vega, como ya lo indica la identidad del primer verso.

2) Adornado de preseas.-Trata el mismo asunto del romance XI de Lope, pero sin tomar de él ningún verso. Es notable que Vicuña Cifuentes haya encontrado en una aldea de Chile una versión oral, muy estropeada, del romance de Pérez de Hita; conserva fielmente un trozo de siete versos. Aprendido quizá de algún ejemplar de las Guerras civiles, posiblemente se trasmitió después por vía oral ${ }^{12}$.

* Además de la versión de la primera Flor, que pasó al Romancero de $\mathbf{1 6 0 0 ,}$ se conserva otra en el ms. de Jacinto López de 1620 y otra en un ms. de la Biblioteca de Palacio, de 1590 a 1600 (2-H-4); ambas ofrecen algunas variantes aceptables.

${ }^{10} \mathrm{El}$ romance fué publicado por Salvá en su Catálogo, vol. I, pág. 68b; Salvá lo tomó de la Academia de los Nocturnos, ms. que era de su propiedad.

11 Además de la versión que recogió el Romancero de 1600 , puede leerse este romance en el citado ms. 2-H-4 de la Biblioteca de Palacio.

12 Julio Vicuña Cifuentes, Romancero popular y vulgar chileno, Santiago de Chile, 1912, pág. 541. 
Góngora conocía éste u otro romance de las Guerras civiles, porque cita a la pareja Lindaraja-Gazul ${ }^{13}$.

3) De honor y trofeos lleno.-Vuelve Gazul triunfante de Gelves, y Lindaraja le acoge en su jardín y le corona con una guirnalda. La enumeración de flores ha sido sugerida por el romance $\mathrm{X}$ de Lope.

4) Sale la estrella de Venus.-Pérez de Hita, después de dar fin a la historia de los amores de Gazul con la celebración de las bodas, convertidos los dos esposos al cristianismo, se arrepintió de no haber incluído el romance que estaba más en boga; dice que "por no ser bueno, ni haberlo entendido el autor que le hizo, no le puso en su lugar". Se decide a copiarlo al final, y después de hacerlo, con bastante fidelidad, insiste en que el romance da "muy fuera del blanco de la historia, y aunque tiene buenos conceptos, son algo fríos, y su tonada no es nada gustosa repecto de la intricación que lleva, y también porque a los fines viene a declararse la historia suya. Agora, salva paz de su autor, va algo enmendado". Pérez de Hita acusa al autor de haber incurrido en anacronismos: ¡como si las Guerras civiles fueran una historia verdadera!

5) No de tal braveza lleno.-Es una mala imitación del tan criticado romance de Lope Sale la estrella de Venus.

6) Estando toda la corte.-Como dejamos dicho, es ajeno a los amores de Gazul. Es inferior al modelo, y no hace alusión al famoso rejoneador de la casa del Algaba.

La estrella de Venus fué indudablemente la composición del Romancero Nuevo que adquirió mayor fama. Escrita hacia 1583, la encontramos en la primera Flor de 1588 y un año después aparece copiada en el Cancionero Classense de Ravena. También de 1589 es el ms. $3_{168}$ de la B. N. M., donde hay otra versión. La atribución de este romance a Lope de Vega se encuentra ya en un soneto de su coetáneo y enemigo Góngora, que satiriza un buen número de las obras de aquél:

Aquí del Conde Claros, dijo, y luego se agregaron a Lope sus secuaces; con la Estrella de Venus cien rapaces y con mil soliloquios sólo un ciego.

En varios romances, unos de Lope y otros ajenos, insertos en el Romancero de 1600 , se alude a La estrella de Venus, y en la parte $6^{\text {a }}$ hay una glosa de los cuarenta primeros versos. Un lector del siglo XVII puso notas marginales a un ejemplar del Romancero general de 1604 , que se conserva en la B. N. M. (R-2171); al final del romance Mirando está Lisardo añadió unos versos según los cuales Lope hizo creer

${ }_{13}$ El Doctor Carlino, comedia de 1613. Obras poéticas de Góngora, ed. Foulché-Delbosc, vol. II, pág. 142. 
falsamente a Elena que había escrito La estrella de Venus inspirado por ella:

$$
\begin{aligned}
& \text { Aquella estrella de Venus } \\
& \text { compuse por cierto eclipse, } \\
& \text { y después para engañarla } \\
& \text { que fué por su causa dije*. }
\end{aligned}
$$

Lope sentía predilección por este romance; no sólo aludió a él en otros de su clase, sino también en comedias de su época juvenil. En El sol parado, obra tan rica en elementos tradicionales, Zaida y Gazul forman la pareja secundaria y representan con todo detalle la acción del romance: mientras Gazul está en la guerra, Zaida se casa con Abenzaide, obligada por su codicioso padre. Y luego sigue, acompañando a la acción una larga glosa del romance, ligeramente abreviado. $\mathrm{Al}$ publicar Lope esta comedia en 1621 , dice en la dedicatoria: "parece que ando ahora a recoger las flores que se perdieron en mi juventud, en los mayores años". En Las ferias de Madrid, fechada en $15^{89}$, incluye Lope los versos 41 y 42 de este romance. También hay alusión a él en La Dorotea.

La estrella de Venus no sólo estuvo de moda entre los rapaces que dijo Góngora, sino que muchos escritores alabaron alguno de sus versos o hicieron referencia a ellos. En La famosa toledana (de hacia 1591), Juan de Quirós da testimonio de la popularidad del romance, diciendo: "No queda venta ni monte / do no se cierre este moro". El negro Luis de El celoso extremeño (1613), de "romances, sólo éste sabía cantar". También en el Quijote de Avellaneda (1614) se incluyen los dos primeros versos del romance. En sus Conceptos espirituales (160o) Alonso de Ledesma hizo una glosa a lo divino, de las más hábiles en su género, sin irreverencias ni retorcimientos de adaptación, tal que sin conocer la versión profana, pudiera pasar bien por original. En el Baile del ;Ay, ay, ay! y el Sotillo, publicado en la Quinta parte de comedias de diferentes autores (1616), un lacayo canta al son de su guitarrilla ocho versos del romance y dos fregonas van comentándole en burla uno a uno. Luis Quiñones de Benavente, en el entremés cantado de Los planetas ( $c a .16{ }^{1} 1$ ), saca a escena la Estrella de Venus introduciéndola con los tan repetidos primeros dos versos. También en el entremés de Don Gaiferos Quiñones cita esos versos en una especie de ensalada de romances. Salas Barbadillo, en El cortesano descortés (1621), lo tiene por un romanzón comido de roña y polilla. Se encuentra asimismo citado en El donado hablador de Alcalá Yáñez (2ª parte, de 1626); Quevedo lo recuerda en La hora

* Estos versos, algo cambiados, están en el Ramillete de flores (Lisboa, Antonio Álvarez, 1593), como puede verse en el artículo de José F. Montesinos sobre esta compilación (NRFH, VI, 1952, pág. 364, núm. 29)--[NoTA DE LA REDACCión]. 
de todos (1625); Calderón glosa los cuatro primeros versos al final de su zarzuela La púrpura de la rosa (1660), y unos años más tarde (1665) Miguel de Barros introduce por dos veces versos del mismo romance en las Poesias famosas y comedias. Más de tres cuartos de siglo se mantuvo la Estrella de Venus lanzando destellos en nuestra literatura. Y todavía, a fines del siglo xviı, cuando nuestro Romancero estaba despreciado, resuena un eco lejano de la Estrella en $\mathrm{El}$ Barón (1787) de Nicolás Fernández de Moratín. Después de pasado el furor del romanticismo, Antonio de Mendoza repite los primeros versos en su comedia La Maya, estrenada en 1869 .

También el romance Por la plaza de Sanlúcar tuvo repercusión en otras composiciones del Romancero de 1600 . Lope lo recordó tardíamente, haciendo cantar dieciséis versos suyos en su comedia El Marqués de las Navas (1624). José F. Montesinos, al publicar el autógrafo de esa comedia en Teatro Antiguo Español, vol. VI, copia en nota el romance de las Guerras civiles y las variantes del Romancero general, sospechando que pueda ser de Lope de Vega y que se refiera a sucesos amorosos de su juventud. El querer identificar aquí a Zaida con Elena Osorio, como ocurre en otro ciclo de romances moriscos, le desvía de la recta interpretación. Este romance fué muy alabado por Gracián, quien por tres veces cita versos de él como modelo de bien decir ${ }^{14}$.

El olvidar estos primeros amores de Lope para no tomar en cuenta más que la pasión por Elena ha hecho que varios críticos no dieran la debida interpretación a obras en que descubrían rasgos biográficos, empezando con $E l$ verdadero amante.

Madrid.

María Goyri de Menéndez Pidal

${ }_{14}$ Agudeza y arte de ingenio, ed. de Madrid, 1664, págs. 33, 111 y 163 . 